\title{
Morphology and Protein Composition of Gas Vesicles from Wild Type and Gas Vacuole Defective Strains of Halobacterium salinarium Strain 5
}

\author{
By ROBERT D. SIMON \\ Department of Biology, The University of Rochester, Rochester, New York 14627, U.S.A.
}

(Received 18 November 1980; revised 22 January 1981)

The morphology and protein composition of gas vesicles isolated from wild-type and gas vacuole defective ( $\mathrm{gv}^{\text {def }}$ ) isolates of Halobacterium salinarium strain 5 have been analysed. Two general vesicle shapes were found: spindles, and cylinders with short biconical ends. Wild-type strains contained a majority of spindle-shaped vesicles $(94 \%)$, while $69 \%$ of the vesicles in $\mathbf{g v}^{\text {def }}$ strains were cylindrical. Electrophoretic analysis of gas vesicle proteins showed that vesicle preparations contained only a single major protein species. In addition, the polypeptide in vesicles from the $\mathrm{gv}^{\text {def }}$ strain migrated more slowly than that from the wild-type strain. From the rates of electrophoretic migration, the molecular weights of gas vacuole proteins in the wild-type and $\mathrm{gv}^{\text {def }}$ strains were estimated as 16800 and 18200 , respectively.

Data provided here are consistent with the suggestion that polypeptide processing may be involved in the formation and assembly of gas vesicles in Halobacterium.

\section{INTRODUCTION}

Halobacteria are aquatic micro-organisms having an absolute growth requirement for $\mathrm{NaCl}$ at concentrations above $2 \mathrm{M}$ (Lanyi, 1974). Several isolates of halobacteria contain gas vesicles, i.e. proteinaceous structures which enclose a gas-filled space (Walsby, 1978). Negatively stained preparations of gas vesicles from a variety of Halobacterium species have been examined in the electron microscope (Larsen et al., 1967; Stoeckenius \& Kunau, 1968; Cohen-Bazire et al., 1969), and the majority appear as spindle-shaped bodies with maximum widths $<250 \mathrm{~nm}$. This morphology of gas vesicles differs from that seen in most other micro-organisms, as the gas vesicles from aquatic prokaryotes usually have a cylindrical body of varying length (Walsby, 1978). However, Cohen-Bazire et al. (1969) have noted that in the Delft strain of Halobacterium, long cylindrical gas vesicles do appear at low frequency, and that these vesicles have a smaller maximum diameter $(<137 \mathrm{~mm})$ than the spindle-shaped vesicles. Other published electron micrographs occasionally show two types of vesicles in Halobacterium (Stoeckenius \& Kunau, 1968), and in each case, the cylindrical vesicles have a smaller diameter than the spindle-shaped vesicles.

Falkenberg (1974) isolated the gas vacuoles from Halobacterium salinarium strain 5 and showed, using an acid/urea electrophoretic system, that the gas vacuole preparations contained two proteins with molecular weights of 15100 and 12900 . The larger protein comprised $80 \%$ of the total preparation. The observation of two protein types is unusual since the gas vacuoles isolated thus far from other micro-organisms (Jones \& Jost, 1971; Falkenberg et al., 1972; Konopka et al., 1977) consist of a single protein.

The light-scattering properties of gas vacuoles give a distinctive creamy colour to Halobacterium colonies grown on agar-containing medium, and it is relatively easy to identify strains in which there are mutations in the production of gas vacuoles (Larsen et al., 1967). Halobacterium salinarium strain 5 spontaneously produces such mutants at a frequency of 
$1 \%$ (Simon, 1978). Two types of strains can be found: those truly lacking gas vacuoles $\left(\mathrm{gv}^{-}\right)$ which produce transparent colonies; and those which produce opaque colonies because the cells have less gas vacuoles than the wild-type ( $\left.\mathrm{gv}^{\text {def }}\right)$. Clones of the latter type often initially appear as clear $\mathrm{gv}^{-}$colonies but become opaque as the cells age. This time delay can cause $\mathrm{gv}^{\mathrm{def}}$ strains to be initially mislabelled as $\mathrm{gv}^{-}$(Simon, 1978). The identification of defective strains producing small amounts of gas vacuoles can be carried out either by pressure nephelometry (Walsby, 1971) or by examination of negatively stained preparations in the electron microscope. More than $99 \%$ of the spontaneous gas vacuole mutations are of the $\mathrm{gv}^{\text {def }}$ type. Simon (1978) reported that $H$. salinarium strain 5 contained three separate size classes of plasmid DNA and that the spontaneous appearance of $\mathrm{gv}^{\text {def }}$ strains was correlated with the disappearance of a plasmid of $44 \times 10^{6}$ daltons (pRDS102).

This report provides an analysis of the morphology and protein composition of gas vesicles isolated from wild-type and $\mathrm{gv}^{\text {def }}$ strains of $H$. salinarium strain 5 . It is shown that the spontaneous $\mathrm{gv}^{\text {def }}$ strains produce gas vesicles which differ from those in the wild-type strain in both morphology and protein composition.

\section{METHODS}

Bacterial strains and growth conditions. Halobacterium salinarium strain 5 was a gift of Dr Helge Larsen (University of Trondheim, Norway). Spontaneous gv def strains $(7702,7705$ and 7708$)$ were isolated as previously described (Simon, 1978); all lack the plasmid pRDS102. Cells were grown on the medium of Larsen et al. (1967) at $42{ }^{\circ} \mathrm{C}$ either as shake cultures or on plates solidified with $1.8 \%(\mathrm{w} / \mathrm{v})$ agar. Dilutions for the agar plates were made with growth media, and the plates were incubated for at least $10 \mathrm{~d}$ for wild-type cells to express gas vacuoles. Plates inoculated with $g v^{\text {def }}$ strains were initially grown for $10 \mathrm{~d}$ at $42{ }^{\circ} \mathrm{C}$ and then stored for 1 month at room temperature to give time for the expression of gas vacuoles. The colonies produced by $\mathrm{gv}^{\mathrm{def}}$ strains were transparent after $10 \mathrm{~d}$ growth at $42^{\circ} \mathrm{C}$ but became opaque after the prolonged incubation at room temperature. The colonies also turned turbid if incubation was continued at $42{ }^{\circ} \mathrm{C}$ rather than room temperature but, because of the high salt concentration in the media, problems then arose with the plates drying out. Groups of plates were either placed in plastic bags or were wrapped in aluminium foil to retard drying during the incubation periods. Colonies were scored as $\mathrm{gv}^{\mathrm{der}}$ if, after prolonged growth, they did not show the creamy colour of the wild-type colonies.

Isolation of gas vacuoles. Intact gas vacuoles were isolated using a modification of the method given by Cohen-Bazire et al. (1969). Cells were grown on agar-containing medium in $100 \mathrm{~mm}$ Petri dishes and were washed from each dish with $15 \mathrm{ml}$ of $1.0 \mathrm{mM}-\mathrm{MgSO}_{4}$ containing $10 \mu \mathrm{g}$ DNAase $\mathrm{I} \mathrm{ml}^{-1}$. The resulting suspension was incubated at $37^{\circ} \mathrm{C}$ for $3 \mathrm{~h}$, during which time cells were totally lysed and the DNAase reduced the initial viscosity so that the centrifugal flotation of gas vacuoles could be carried out (Walsby, 1974). The cell lysate was then made to $10 \%(\mathrm{w} / \mathrm{v}) \mathrm{NaCl}$ and filtered through two layers of tissue paper into a centrifuge tube. Each tube was overlaid with $5 \%(\mathrm{w} / \mathrm{v}) \mathrm{NaCl}$ and the tubes were centrifuged for $16 \mathrm{~h}$ in a swing-out rotor at $60 \mathrm{~g}$. The intact gas vacuoles floated to the top of the tube under these conditions and were recovered using a Pasteur pipette. After resuspending the gas vacuoles in $5 \%(\mathrm{w} / \mathrm{v}) \mathrm{NaCl}$, they were washed twice more by centrifugal flotation as above and then stored at $4{ }^{\circ} \mathrm{C}$ prior to use.

Electron microscopy and acrylamide gel electrophoresis. Negatively stained preparations of isolated gas vacuoles were prepared for electron microscopy. Dilutions of gas vacuole preparations were applied to carbon-coated collodion grids which were then washed successively with horse-heart cytochrome $c\left(1 \mathrm{mg} \mathrm{m}^{-1}\right)$, water, and $1 \%(\mathrm{w} / \mathrm{v})$ uranyl acetate. The liquid remaining from the last wash was removed by blotting with filter paper. After drying, the grids were examined in a transmission electron microscope (RCA model EU-3). In all gas vacuole preparations examined, intact $T$, bacteriophage was added as an internal size marker. (The diameter of the intact $T$, bacteriophage heads was taken to be $47 \mathrm{~nm}$; Williams, 1953.) Random areas of grids were photographed and size measurements of individual gas vesicles were made on enlargements of the photographs. The diameters of $T$, bacteriophage appearing in the same photographs were also measured. For each gas vesicle, the width at the widest point $(W)$ was recorded along with the length from end to end $(L)$. If the vacuole was cylindrical in shape, the length of the cylindrical portion was also recorded $\left(L^{\prime}\right)$ (Fig. 1). Calculations of volume, surface area and end angle were made by assuming that spindle-shaped gas vesicles were ideally bipolar, consisting of two cones of base $W$ and height $L / 2$, and that cylindrical gas vesicles had biconal ends [base $W$, height $\left(L-L^{\prime}\right) / 2$ ] interrupted by a cylinder of diameter $W$ and length $L^{\prime}$ (Fig. 1).

Electrophoresis in acrylamide gels containing sodium dodecyl sulphate (SDS) were carried out as described by Studier (1973). Gas vacuole proteins and total cell extracts from various strains were also separated in the acetic 

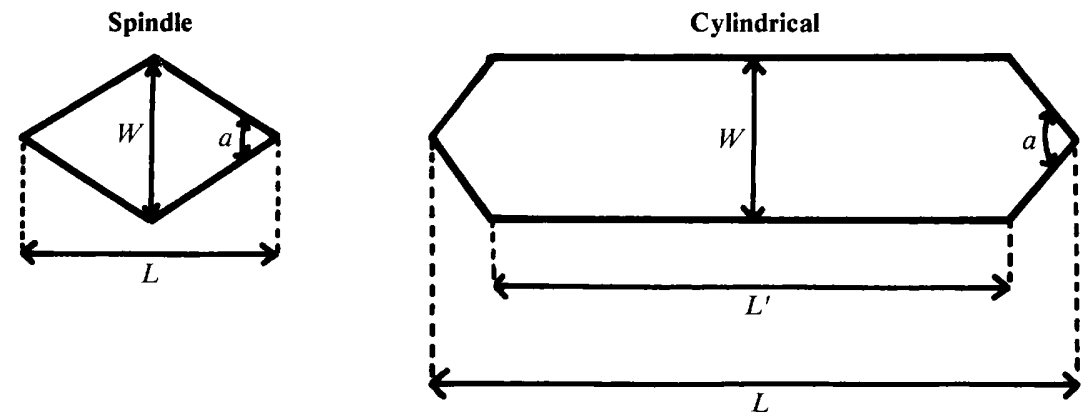

Fig. 1. The two idealized shapes of gas vesicles found in various isolates of Halobacterium salinarium strain 5. When measurements of individual gas vesicles were made from electron micrographs, the width $(W)$ and end-to-end length $(L)$ of each vesicle was recorded, along with the length of the cylindrical portion $\left(L^{\prime}\right)$ for vesicles with a cylindrical shape. Volume, surface area and end angle $(a)$ were calculated from these measurements using the assumptions described in Methods.

acid/urea gel system described by Falkenberg (1974) and on 10\% (w/v) acrylamide gels containing acetic acid/urea/phenol (35:30:10, by wt) (Simon, 1980). Proteins on the gels were stained with Coomassie brilliant blue and photographs of the gels were made using a Polaroid camera.

\section{RES U L T S}

\section{Gas vesicles in the wild-type strain}

Gas vesicle preparations were relatively pure judging by the absence of membranes when material was viewed in the electron microscope, though occasional filaments, thought to be contaminating flagella, were seen. No bands staining with Coomassie blue were seen following SDS gel electrophoresis of up to $100 \mu \mathrm{g}$ purified gas vesicle protein. The majority of gas vesicles isolated from the wild-type strain were spindle-shaped (Fig. 2a; Table 1). However, $6 \%$ of the gas vesicles showed a cylindrical morphology (Fig. $2 a$, arrow), and rarely $(<0.1 \%)$ other forms could be seen. For example, the vesicle shown in Fig. $2(c)$ is a cylinder with an internal taper. No irregular 'monster' forms were seen in any of the preparations examined. A summary of the length and width measurements made from electron micrographs of negatively stained gas vesicles as well as the morphological parameters calculated from the measurements (volume, surface area, end angle) for both spindle-shaped vesicles and cylindrical vesicles are given in Table 1. Cylindrical vesicles were narrower in width but on the average tended to be longer from pole to pole. Cylindrical vesicles also had a larger volume and surface area. In addition, there was a significant

Table 1. Summary of morphological measurements on isolated gas vesicles from the wildtype and $a \mathrm{~g} v^{\text {def }}$ isolate of Halobacterium salinarium strain 5

All numbers are given \pm the standard deviation. For the measurements reported, 114 and 206 gas vesicles were counted in the wild-type and the $\mathrm{gv}^{\text {def }}$ strain, respectively.

\begin{tabular}{|c|c|c|c|c|c|c|c|}
\hline Strain & $\begin{array}{l}\text { Gas vesicle } \\
\text { morphology* }\end{array}$ & $\begin{array}{c}\text { Occurrence } \\
(\%)\end{array}$ & $\begin{array}{l}\text { Length* } \\
\quad(\mathrm{nm})\end{array}$ & $\begin{array}{l}\text { Width* } \\
(\mathrm{nm})\end{array}$ & $\underset{\substack{10^{-5} \times \\
\left(\mathrm{nm}^{3}\right)}}{\text { Volume }} \dagger$ & $\begin{array}{c}10^{-4} \times \\
\text { Surface area } † \\
\left(\mathrm{~nm}^{2}\right)\end{array}$ & $\begin{array}{c}\text { End angle } \dagger \\
\text { (degrees) }\end{array}$ \\
\hline Wild-type & $\begin{array}{l}\text { Spindle } \\
\text { Cylindrical }\end{array}$ & $\begin{array}{r}93 \cdot 9 \\
6 \cdot 1\end{array}$ & $\begin{array}{l}239 \pm 55 \\
311 \pm 91\end{array}$ & $\begin{array}{l}197 \pm 41 \\
136 \pm 22\end{array}$ & $\begin{array}{l}2.5 \pm 1.6 \\
2.9 \pm 1.0\end{array}$ & $\begin{array}{r}9 \cdot 6 \pm 4 \cdot 0 \\
11 \cdot 2 \pm 3 \cdot 3\end{array}$ & $\begin{array}{l}77.6 \pm 8.6 \\
94.8 \pm 9.6\end{array}$ \\
\hline $\begin{array}{l}g^{\text {def }} \\
(7708)\end{array}$ & $\begin{array}{l}\text { Spindle } \\
\text { Cylindrical }\end{array}$ & $\begin{array}{l}31 \cdot 1 \\
68 \cdot 9\end{array}$ & $\begin{array}{l}238 \pm 33 \\
535 \pm 270\end{array}$ & $\begin{array}{l}175 \pm 23 \\
127 \pm 17\end{array}$ & $\begin{array}{l}2.0 \pm 0.6 \\
5.3 \pm 2.6\end{array}$ & $\begin{array}{r}8 \cdot 3 \pm 1 \cdot 7 \\
19.4 \pm 9 \cdot 0\end{array}$ & $\begin{array}{l}74.5 \pm 7.4 \\
99.3 \pm 8 \cdot 8\end{array}$ \\
\hline
\end{tabular}

* See Fig. 1 for the definition of shape.

$\dagger$ Morphological parameters calculated using the assumptions given in Methods. 

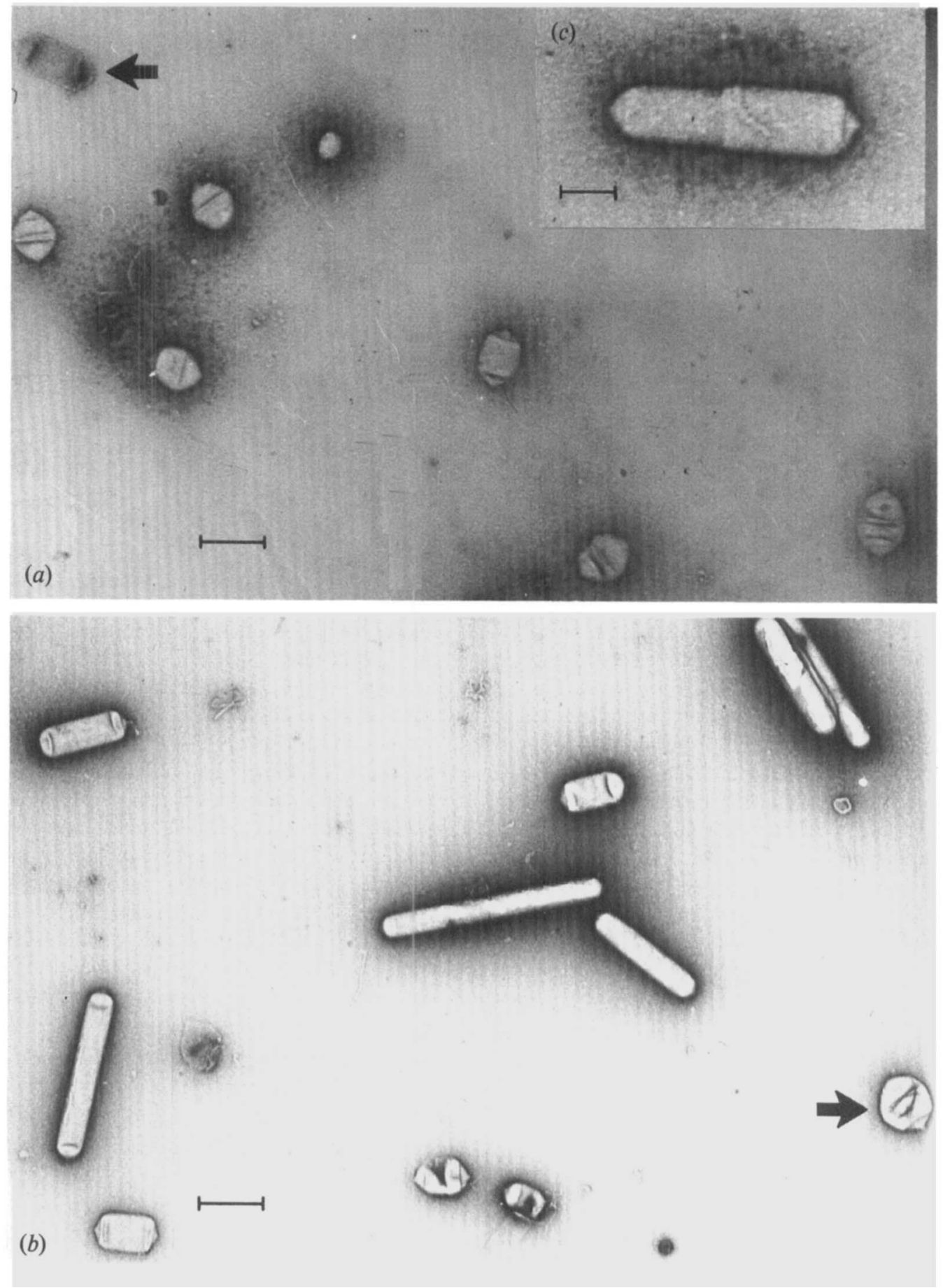

Fig. 2. Electron micrographs of negatively stained preparations of purified gas vesicles from wild-type and $\mathrm{gv}^{\text {def }}$ isolates of Halobacterium salinarium strain 5. (a) Preparation from the wild-type strain in which the majority of vesicles are spindle-shaped; the arrow designates a vesicle with cylindrical morphology. (b) Preparation from strain 7708, a gvef isolate (Simon, 1978), in which the majority of vesicles show cylindrical morphology; the arrow marks a vesicle with spindle shape. (c) Single isolated vesicle from wild-type preparation which is cylindrical in morphology but shows an internal taper. The bar markers represent $250 \mathrm{~nm}$ in $(a)$ and $(b)$ and $125 \mathrm{~nm}$ in $(c)$. 


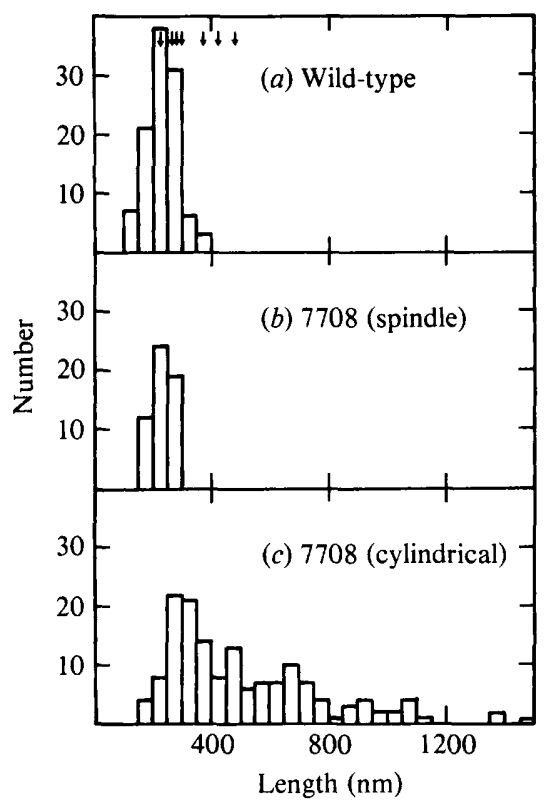

Fig. 3

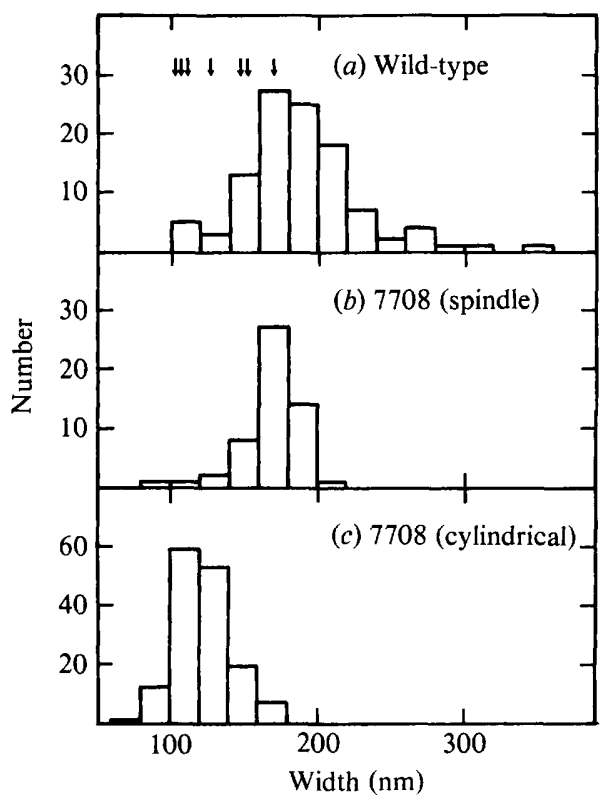

Fig. 4

Fig. 3. Distribution of end-to-end lengths of gas vesicles purified from the wild-type and $g v^{\text {def }}$ isolates of Halobacterium salinarium strain 5: (a) spindle-shaped gas vesicles from the wild-type strain (the arrows denote the length of seven vesicles with cylindrical morphology measured in the same preparation); $(b)$ spindle-shaped gas vesicles in a preparation from a gver $(7708)$ isolate; $(c)$ cylindrical gas vesicles in a preparation from a $\mathrm{gv}^{\text {def }}(7708)$ isolate.

Fig. 4. Distribution of widths of gas vesicles purified from the wild-type and $g^{\text {def }}$ isolates of Halobacterium salinarium strain 5: (a) spindle-shaped gas vesicles from the wild-type strain (the arrows denote the width of seven vesicles with cylindrical morphology measured in the same preparation); $(b)$ spindle-shaped gas vesicles in a preparation from a gver $(7708)$ isolate; $(c)$ cylindrical gas vesicles in a preparation from a $\mathrm{gv}^{\text {def }}(7708)$ isolate.

difference in the end angles of the two vesicle types, with the cylindrical vesicles having blunter ends. More detailed presentations of the distributions of length and width measurements for the spindle-shaped gas vesicles are given in Figs. $3(a)$ and $4(a)$. Only seven cylindrical vesicles were analysed in the sample studied, and the lengths and widths of these vesicles are indicated by the arrows above the histograms. It is evident that, as a group, the cylindrical vesicles differed from the spindle-shaped vesicles.

Figure 5 presents a graph of length versus width for the 106 spindle-shaped gas vesicles measured from the wild-type strain. The points define a line (correlation coefficient 0.88 ) with a slope of 1.39 .

\section{Gas vesicles in $g v^{\text {def }}$ strains}

The gas vacuole defective strain 7708, which lacks plasmid pRDS102, produced transparent colonies after $10 \mathrm{~d}$ growth at $42^{\circ} \mathrm{C}$. However, on further incubation, the colonies became opaque and the presence of gas vacuoles was indicated by the observation that brief pressurization decreased the turbidity of cell suspensions prepared from old cultures. Following osmotic cell lysis, gas vacuoles could be isolated in a manner identical to those from wild-type cultures. Examination of negatively stained samples of these vesicles in the electron microscope showed that they had a strikingly different morphology from those in the wild-type strain (Fig. 2 b). In strain $7708,69 \%$ of the vesicles were cylindrical and only $31 \%$ 


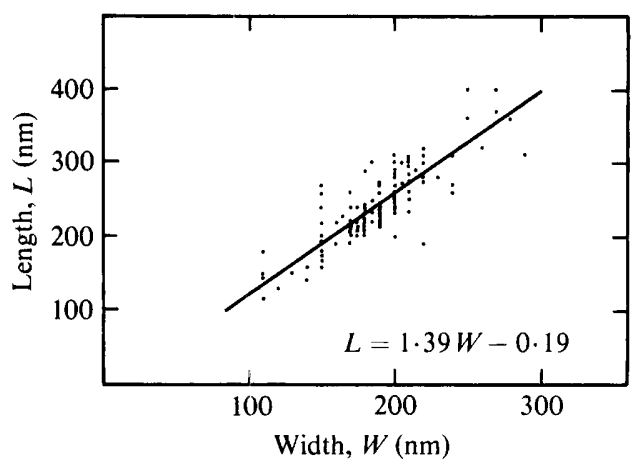

Fig. 5. Length plotted as a function of width for the spindle-shaped gas vesicles from the wild-type isolate of Halobacterium salinarium strain 5 . Individual vesicles are denoted by dots, and the best-fit regression line calculated for the data is indicated.

showed the spindle-shaped morphology (Table 1). As in the wild-type, the cylindrical vesicles had a narrower diameter than the spindle-shaped vesicles. The average length of cylindrical vesicles was larger than those with spindle shape, and the high standard deviation for the cylindrical vesicle length was a reflection of the great range of lengths found for these vesicle types. While the range of lengths of spindle-shaped vesicles was 180 to $300 \mathrm{~nm}$, that for the cylindrical vesicles was 180 to $1480 \mathrm{~nm}$. The distributions of length and width measurements for both vesicle types measured in samples from strain 7708 are given in Figs. $3(b, c)$ and $4(b, c)$. There were similarities between the lengths and widths of spindle-shaped vesicles from both the wild-type strain and strain 7708 , as well as similarities between the widths of cylindrical vesicles in the two strains. Cylindrical vesicles were longer in the $\mathrm{gv}^{\text {def }}$ strain, but this difference may only result from the limited number of cylindrical vesicles measured in wild-type preparations. Even though the cylindrical vesicles in strain 7708 were narrower, the extraordinary lengths of some of these vesicles resulted in this class of vesicle types having greater average volume and surface area than spindle-shaped vesicles (Table 1). The results of observations on gas vesicles from strains 7702 and 7705 , two other spontaneous $\mathrm{gv}^{\text {def }}$ strains which lack plasmid pRDS102, were similar to those reported here for strain 7708 , indicating that the results for strain 7708 were a general phenomenon of spontaneous gv $^{\text {def }}$ strains.

\section{Protein composition of gas vacuole preparations}

Preparations of gas vacuoles boiled in solutions containing $1 \%(\mathrm{w} / \mathrm{v})$ SDS lost turbidity and formed solutions with limited translucence. However, the proteins were not completely solubilized by this treatment since no bands staining with Coomassie blue were detected following electrophoresis on $10 \%(\mathrm{w} / \mathrm{v})$ acrylamide gels containing 0.1 to $1.0 \%$ SDS. The addition of other detergents such as Triton X-100, Brij-58 or deoxycholic acid did not increase the solubility of gas vacuole proteins either in the absence or presence of different concentrations of SDS.

When the gas vacuoles were solubilized in mixtures of phenol/acetic acid/urea and then electrophoresed on acrylamide gels containing acetic acid/urea, the majority of material staining with Coomassie blue failed to enter the gel, but a lightly staining band could be seen. This band migrated at a rate similar to that for a protein in the size class of gas vacuole proteins. In contrast to the report of Falkenberg (1974), only a single band of staining material was resolved using gel systems of this type.

Using $10 \%(\mathrm{w} / \mathrm{v})$ acrylamide gels containing acetic acid/urea/phenol all the material in a gas vacuole preparation migrated into the gel (Fig. 6). The majority of protein from gas vacuole preparations ran as a single band on a $10 \%(\mathrm{w} / \mathrm{v})$ acrylamide gel although occasionally preparations contained a minor contaminant. The amount of this contaminant, 


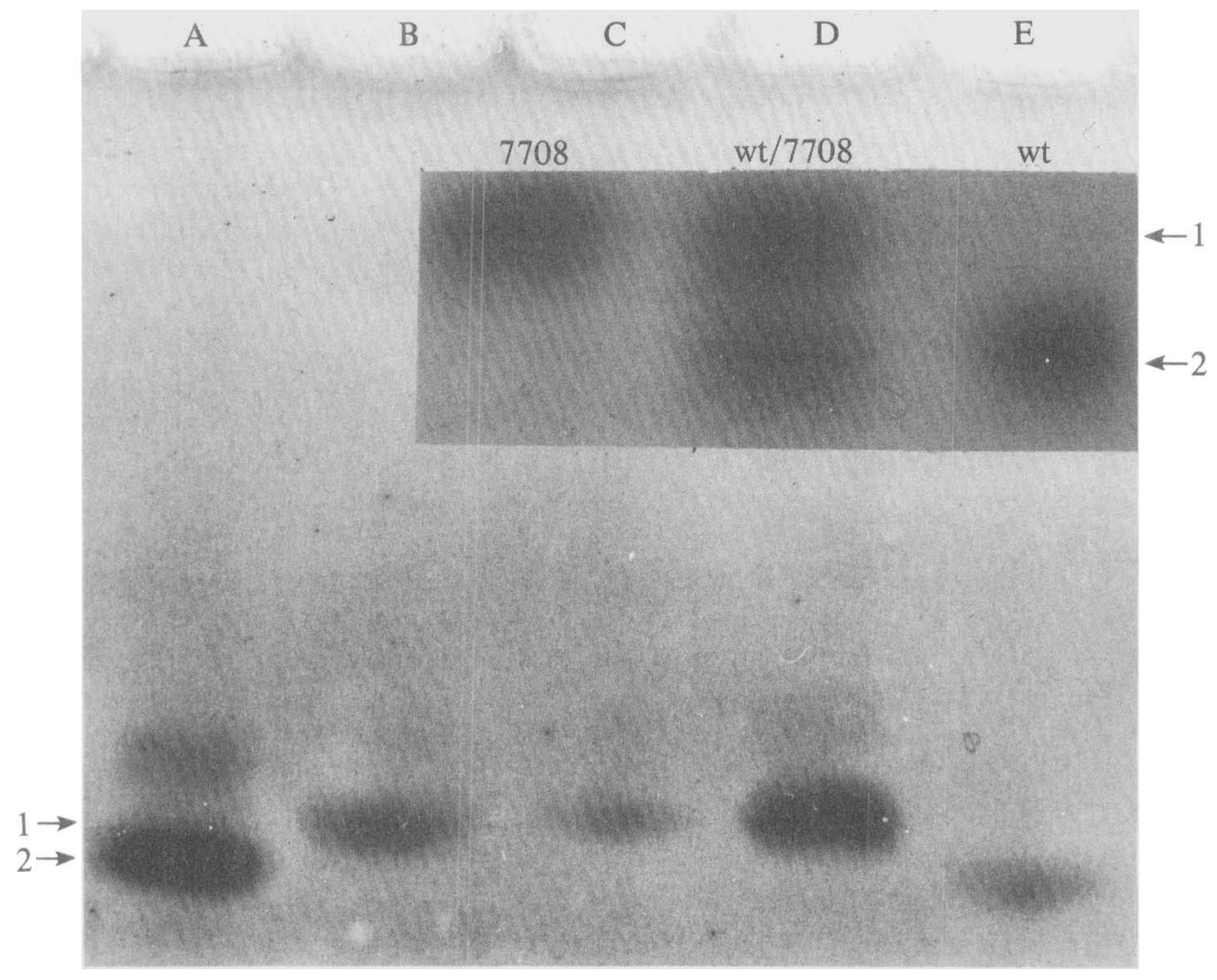

Fig. 6. Electrophoresis of gas vacuole preparations from various isolates of Halobacterium salinarium strain 5 using a $10 \%$ acrylamide gel containing acetic acid/urea/phenol. Lanes $\mathrm{A}$ and $\mathrm{E}$ show a gas vacuole preparation from the wild-type strain. Lanes B, C and D show gas vacuole preparations from the $\mathrm{gv}^{\text {def }}$ strains 7702,7705 and 7708 , respectively. The inset shows the gas vacuole polypeptides in wild-type (wt) and $\mathrm{gv}^{\text {def }}$ (7708) strains which have been electrophoresed separately and together (wt/7708). The arrows 1 and 2 refer to the gas vacuole polypeptide band in the $\mathrm{gv}^{\text {def }}$ and wild-type strains, respectively.

which never constituted more than $5 \%$ of the total staining material, varied from preparation to preparation and it was completely absent from some preparations, suggesting that it was either not a normal constituent of gas vacuoles or that it was easily removed during gas vacuole purification. Strikingly, the protein in gas vesicles isolated from the wild-type strain (Fig. 6, lanes A, E) migrated faster on gels than that isolated from gv ${ }^{\text {def }}$ strains (Fig. 6, lanes B, C, D) and the two protein types could be separated when co-electrophoresed (Fig. 6, inset). There was a logarithmic-linear relationship between electrophoretic mobility and molecular weight in the gel system containing acetic acid/urea/phenol, although several proteins (e.g. bovine serum albumin and histones) showed anomalous behaviour (Simon, 1980). Using a standard curve (not shown), it was estimated that the electrophoretic migration was consistent with molecular weights of 16800 and 18200 for the gas vacuole proteins from the wild-type strain and $\mathrm{gv}^{\text {def }}$ strains, respectively.

\section{DISCUSSION}

While cylindrical vesicles have been noted in various Halobacterium strains, details about their frequency and characteristics have not been reported. In the population of gas vesicles isolated from the wild-type strain studied here, up to $6 \%$ of the vesicles were cylindrical. Vesicles of this type differ from the majority of spindle-shaped vesicles in a number of 
important characteristics including width, length and end angle. The presence of a large number of cylindrical vesicles is a characteristic of $\mathrm{gv}^{\text {def }}$ strains (see below). These strains are spontaneously produced at a high frequency, and under the conditions of normal growth reported here, the $\mathrm{gv}^{\text {def }}$ character is a neutral mutation which accumulates if the wild-type strain is subcultured over a long period of time (Larsen et al., 1967). Thus, some component of the percentage of cylindrical vesicles which are found in the isolated preparations of the wild-type strain would be a function of the percentage of $\mathrm{gv}^{\text {def }}$ cell types in the culture used for the gas vacuole isolation.

While the morphology of $\mathrm{gv}^{\text {def }}$ vesicles is different from the wild-type (69\% showed cylindrical morphology and only $31 \%$ were spindle-shaped), the similarities between the morphological parameters for the same vesicle type from wild-type and $\mathrm{gv}^{\mathrm{def}}$ strains indicate that there may be a limited number of configurations by which gas vacuoles can be assembled. Thus, even though the apparent sizes of the gas vacuole polypeptides are different in the two strains (see below), only two vesicle types may be formed. Since the $\mathrm{gv}^{\mathrm{def}}$ strains do not revert to wild-type spontaneously, the presence of spindle-shaped gas vesicles in the defective strains cannot be explained by genetic reversion. But the changes in the protein subunit which clearly affect the timing and level of gas vesicle synthesis in the $\mathrm{gv}^{\text {def }}$ strains may also affect the ratio of the limited number of gas vesicle forms which can be assembled. The possibility that one cell only produces a single vesicle form while the second form is produced by a different class of bacteria must be considered. However, vacuoles produced from clonal cultures always produce both types of morphology. In addition, an electron micrograph of a freeze-fractured wild-type cell of Halobacterium shows both cylindrical and spindle-shaped vesicles (Walsby, 1972).

Waaland \& Branton (1969) have examined the shapes of gas vesicles following the induction of gas vacuole synthesis in the filamentous cyanobacterium Nostoc. They suggested that gas vesicle assembly begins at the poles and proceeds by the addition of new material in the central region between the two poles. The end angle is fixed early and the poles grow apart. In cylindrical vesicles the angle of addition changes at some critical size and the cylindrical portion is formed. The size of the cylindrical portion is then only a reflection of the number of subunits which are added to the central part of the vesicle. If this hypothesis is correct, there should be a linear relationship between the length and width of a population of spindle-shaped gas vesicles. Figure 5 demonstrates that there was such a relationship for spindle-shaped vesicles in the wild-type strain. This type of correlation cannot be made with cylindrical vesicles because the differences in length result from changes in the size of the cylindrical portion and it is not possible to identify cylindrical vesicles before the cylindrical portion is assembled. If the assembly hypothesis of Waaland \& Branton (1969) is correct, the fact that the two morphological types of vesicles have different populations of end angles would suggest that the two vesicle types are already distinguishable at the beginning of assembly, and that neither vesicle type can be directly transformed into the other.

There is little understanding as to what regulates gas vesicle assembly, but the fact that two different morphologies result from a single polypeptide type (see below) would suggest that factors other than the nature of the polypeptide subunit must be involved. The surface area and volume of the two vesicle classes are different, apparently even within the same cell milieu. Thus, certain physical properties, such as those associated with vesicle size (e.g. surface tension), do not in themselves limit gas vesicle size.

Falkenberg (1974) reported the isolation of two protein species from gas vesicles of the same strain of Halobacterium as used here. However, with his electrophoretic system I found that most of the protein failed to enter the acrylamide gel and only one band staining with Coomassie blue could be seen. With a system which contained $10 \%(\mathrm{w} / \mathrm{v})$ phenol in addition to acetic acid/urea, all the gas vacuole protein migrated into the gel, although each preparation still produced only a single band. Falkenberg (1974) grew Halobacterium at $37^{\circ} \mathrm{C}$ and lysed the cells by overnight treatment with $\mathrm{NaOH}$. However, using these 
conditions for bacterial growth and vacuole isolation, I still found only a single band following acrylamide gel electrophoresis (data not shown). The polypeptide in the $\mathrm{gv}^{\mathrm{def}}$ strains 7702, 7705 and 7708 had a lower electrophoretic mobility than that from the wild-type bacteria (Fig. 6). Because gv ${ }^{\text {def }}$ cell types accumulate spontaneously in wild-type cultures without periodic recloning, it is also possible that gas vacuole preparations containing two species of polypeptides with differing molecular weights could be isolated. However, this is an unlikely explanation for the two proteins identified by Falkenberg (1974) because his minor polypeptide had a lower molecular weight than the major polypeptide.

The data presented are consistent with the suggestion that in the wild-type strain the gas vacuole protein is processed prior to assembly, and that plasmid pRDS102 encodes for a portion of the processing system. Thus, in strains lacking pRDS102 the gas vacuole polypeptide is transcribed, but in the absence of processing the larger precursor accumulates and there is a delay in the synthesis. Additionally, the unprocessed polypeptide could still form gas vacuoles, but to a smaller extent, and more significantly, the assembly process might be different so that a class of vacuoles with cylindrical form is favoured. Experiments to examine the extent and role of protein processing in the synthesis of gas vacuoles are presently in progress.

I wish to thank M. Shilo for providing facilities with which to prepare the manuscript, Rachel Yehezkel for secretarial help, and Dr A. E. Walsby for a valuable discussion and a critical reading of the manuscript. Dr David Hinkle supplied the $\mathrm{T}$, bacteriophage. Dr Joanna Olmsted and Mr John Cox were invaluable sources of information on the techniques of electron microscopy. This work was supported in part by grant PCM 77-202322 from the National Science Foundation.

\section{REFERENCES}

Cohen-Bazire, G., Kunisawa, R. \& Pfennig, N. (1969). Comparative study of the structure of gas vacuoles. Journal of Bacteriology 100, 1049-1061.

FALKenBerg, P. (1974). Kjemisk karakterisering av gassvakuole membranen hos halobakterier. Thesis, Institutt for Teknisk Biokjemi Norges, Tekniske Høgskole, Universitetet i Trondheim, Norway.

FALKENBERG, P., BuCKLAND, B. \& Walsby, A. E. (1972). Chemical composition of gas vesicles isolated from Anabaena flos-aquae. Archiv. für Mikrobiologie 85, 304-309.

JONES, D. D. \& JosT, M. (1971). Characterisation of the protein from gas vacuole membranes of the blue-green alga Microcystis aeruginosa. Planta $\mathbf{1 0 0}$, $277-287$.

Konopka, A. E., Lara, J. C. \& Staley, J. T. (1977). Isolation and characterization of gas vesicles from Microcyclus aquaticus. Archives of Microbiology 112, 133-140.

LANYI, J. K. (1974). Salt-dependent properties of proteins from extremely halophilic bacteria. Bacteriological Reviews 38, 272-290.

Larsen, H., Omang, S. \& Steensland, H. (1967). On the gas vacuoles of the halobacteria. Archiv für Mikrobiologie 59, 197-203.

Simon, R. D. (1978). Halobacterium strain 5 contains a plasmid which is correlated with the presence of gas vacuoles. Nature, London 273, 314-317.

SimON, R. D. (1980). Acrylamide gel electrophoresis of hydrophobic proteins: gas vacuole protein. Electrophoresis 1, 172-176.

Stoeckenius, W. \& Kunau, W. H. (1968). Further characterisation of particulate fractions from lysed cell envelopes of Halobacterium halobium and isolation of gas vacuole membranes. Journal of Cell Biology 38, 336-357.

STUDIER, F. W. (1973). Analysis of bacteriophage T7 early RNAs and proteins on slab gels. Journal of Molecular Biology 79, 237-248.

WaAland, J. R. \& Branton, D. (1969). Gas vacuole development in a blue-green alga. Science 163, 1339-1341.

WALSBY, A. E. (1971). The pressure relationships of gas vacuoles. Proceedings of the Royal Society B 178, 301-326.

WALSBY, A. E. (1972). Structure and function of gas vacuoles. Bacteriological Reviews 36, 1-32.

WALSBY, A. E. (1974). Isolation of gas vesicles from blue-green algae. Methods in Enzymology 31, $678-686$.

WALSBY, A. E. (1978). The gas vesicles of aquatic prokaryotes. Symposia of the Society for General Microbiology 28, 327-358.

Williams, R. C. (1953). The shapes and sizes of purified viruses as determined by electron microscopy. Cold Spring Harbor Symposia on Quantitative Biology 18, 185-195. 